\title{
$\square$ Endothelial function in patients with glaucoma
}

\section{Duška Glavaš*, Lovre Bojić, Ratko Ermacora, Bruna Bojić}

University of Split School of Medicine, University Hospital Centre Split, Split, Croatia
RECEIVED:

September 11, 2017

ACCEPTED:

September 26, 2017

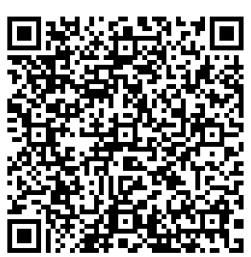

KEYWORDS: endothelial function, flow-mediated dilation, glaucoma.

CITATION: Cardiol Croat. 2017;12(9-10):380. | https://doi.org/10.15836/ccar2017.380

*ADDRESS FOR CORRESPONDENCE: Duška Glavaš, Klinički bolnički centar Split, Spinčićeva 1, HR-21000 Split, Croatia. / Phone: +385-91-5345-088 / E-mail: duska.glavas@gmail.com

ORCID: Duška Glavaš http://orcid.org/0000-0003-2649-0936 • Lovre Bojić http://orcid.org/0000-0001-5649-0756 Ratko Ermacora http://orcid.org/0000-0002-7049-5454 • Bruna Bojić http://orcid.org/0000-0002-5410-8610

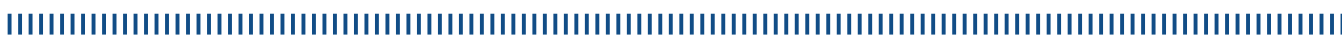

Introduction: Cardiovascular illness are more often observed in glaucoma patients. ${ }^{1}$ The purpose of the study was to assess the ultrasound measurements of the brachial artery flow-mediated dilation (FMD) in patients with glaucoma.

Patients and Methods: Thirty-seven patients with glaucoma and thirty-one healthy controls were included in the study. All glaucoma patients and controls underwent ultrasound measurement of FMD of the brachial artery.

Results: The mean values of brachial FMD were significantly lower among glaucoma group compared with control group ( $15.3 \pm 9.5 \%$ vs $19.8 \pm 9.3 \%$; $=0.04)$. No significant difference was found in brachial artery diameter at rest ( $4.7 \pm 0.6$ vs. $4.9 \pm 0.3 ; \mathrm{p}=0.2)$ between glaucoma patients and controls. The significant difference in brachial artery diameter in hyperemia between patients with glaucoma and control group ( $5.4 \pm 0.6$ vs. $5.9 \pm 0.4 ; \mathrm{p}=0.002$ ) was detected. A negative correlation among brachial FMD and brachial artery diameter at rest was found.

Conclusion: Impaired brachial FMD could indicate presence of systemic vascular endothelial dysfunction in patients with glaucoma.
LITERATURE IIIIIIIIIIIIIIIIIIIIIIIIIIIIIIIIIIIIIIIIIIIIIIIIIIIIIIIIIIIIIIIIIIIIIIIIIIIIIIIIIIIIIIIIIIIIIIIIII 1. Bojić L, Ermacora R, Polić S, Ivanisević $M$, Mandić Z, Rogosić V, et al. Pseudoexfoliation syndrome and asymptomatic myocardial dysfunction. Graefes Arch Clin Exp 0phthalmol. 2005 May;243(5):446-9. https://doi.org/10.1007/s00417-004-1074-9 